\title{
Effects of Nanoscale Surface Lithium Depletion on the Optical Properties and Electronic Band Structures of Lithium Transition Metal Phosphates
}

\author{
Yin Zhang a, b, d, Jose A. Alarco ${ }^{\text {a, }}{ }^{*}$, Jawahar Y. Nerkar ${ }^{\text {a }}$, Adam S. Best ${ }^{\text {b }}$, Graeme A. Snook ${ }^{\mathrm{c}}$, \\ Peter C. Talbot ${ }^{a}$ and Bruce C.C. Cowie ${ }^{\mathrm{e}}$ \\ ${ }^{\text {a }}$ Institute for Future Environments and Science and Engineering Faculty, Queensland University of Technology \\ (QUT), Brisbane, QLD 4001 Australia. \\ ${ }^{\mathrm{b}}$ CSIRO Manufacturing, Private Bag 10, Clayton South, Victoria 3169, Australia. \\ ${ }^{\mathrm{c}}$ CSIRO Mineral Resources, Private Bag 10, Clayton South, Victoria 3169, Australia. \\ ${ }^{\mathrm{d}}$ CRRC Qingdao Sifang Rolling Stock Research Institute Co., Ltd., Qingdao 266031, China. \\ e Australian Synchrotron, 800 Blackburn Road Clayton, Victoria 3168, Australia.
}


Table S1 Lattice parameters of olivine phosphates $\mathrm{LiMPO}_{4}(\mathrm{M}=\mathrm{Mn}, \mathrm{Fe}, \mathrm{Co}, \mathrm{Ni})$.

\begin{tabular}{ccccccc}
\hline & $\begin{array}{c}\text { Database } \\
\text { code }\end{array}$ & Lettice type & $\begin{array}{c}\text { Space } \\
\text { group }\end{array}$ & a / & b / & c / \\
\hline $\mathrm{LiMnPO}_{4}$ & 25834 & Orthorhombic & Pmnb & $6.10(2)$ & $10.46(3)$ & $4.744(10)$ \\
$\mathrm{MnPO}_{4}$ & 99859 & Orthorhombic & Pnma & $10.098(2)$ & $6.204(8)$ & $5.055(7)$ \\
$\mathrm{LiFePO}_{4}$ & 97769 & Orthorhombic & Pnma & $10.332(4)$ & $6.010(5)$ & 4.696 \\
$\mathrm{FePO}_{4}$ & 92199 & Orthorhombic & Pnma & $9.8142(2)$ & $5.7893(2)$ & $4.7820(2)$ \\
$\mathrm{LiCoPO}_{4}$ & 87422 & Orthorhombic & Pnma & $10.2021(3)$ & $5.9227(2)$ & $4.7003(1)$ \\
$\mathrm{CoPO}_{4}$ & $01-078-6161$ & Orthorhombic & Pnma & 9.5670 & 5.7806 & 4.7636 \\
$\mathrm{LiNiPO}_{4}$ & 72929 & Orthorhombic & Pnma & $10.0317(1)$ & $5.8539(1)$ & $4.6768(1)$ \\
$\mathrm{NiPO}_{4}$ & - & - & - & - & - & - \\
\hline
\end{tabular}


Table S2 Mole ratios of lithium, ion and phosphorus obtained by ICP and carbon content for the LiTMPO4 (TM=Mn, Fe, Co and $\mathrm{Ni}$ ) samples.

\begin{tabular}{ccc}
\hline Sample & Li:TM:P & Carbon content/wt.\% \\
\hline $\mathrm{LiMnPO}_{4}$ & $1.14(6): 1: 1.06(1)$ & 0.140 \\
$\mathrm{LiFePO}_{4}$ & $1.01(3): 1: 0.94(8)$ & 0.140 \\
$\mathrm{LiCoPO}_{4}$ & $0.96(7): 1: 0.93(7)$ & 0.029 \\
$\mathrm{LiNiPO}_{4}$ & $1.06(8): 1: 0.98(4)$ & 0.000 \\
\hline
\end{tabular}



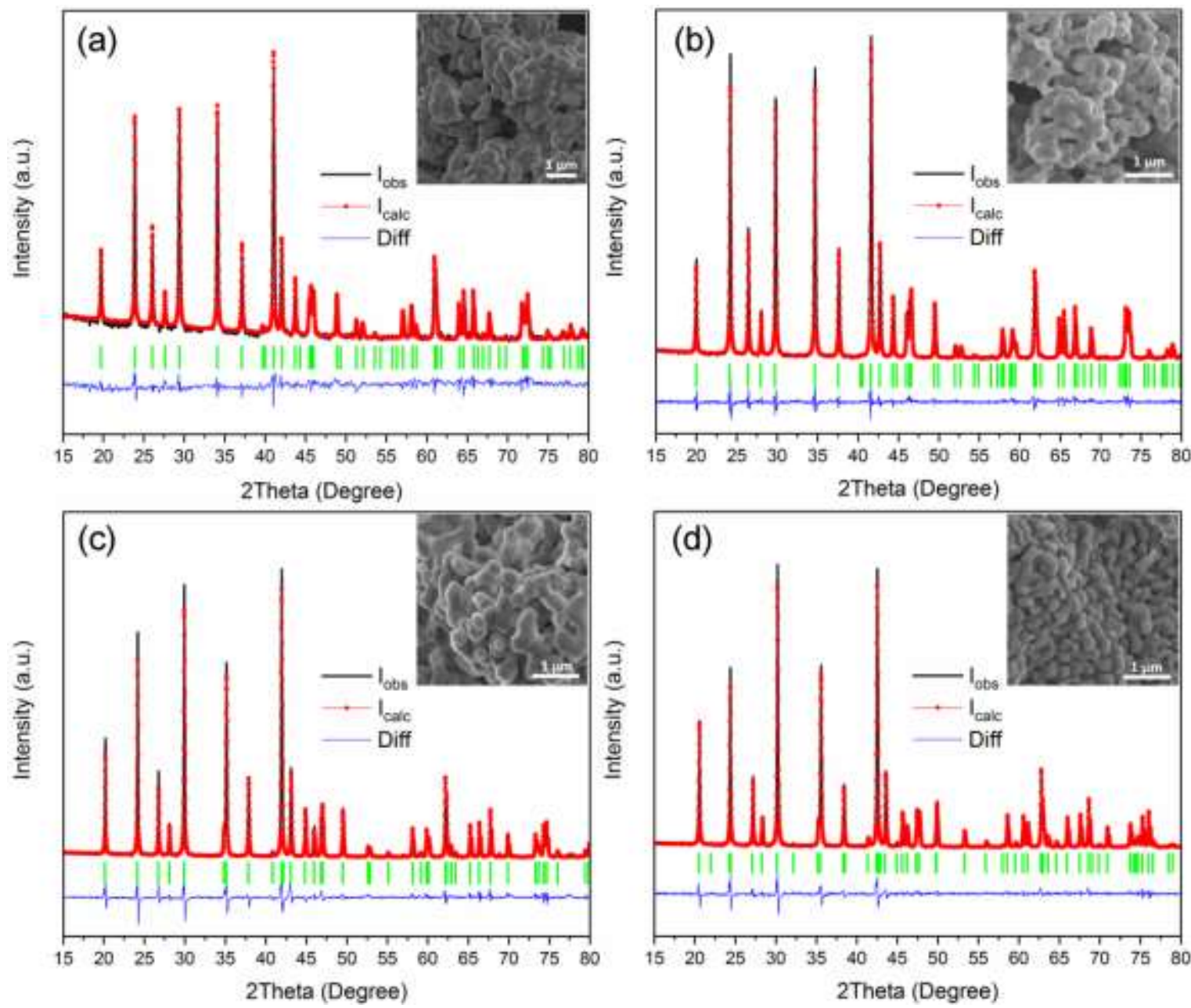

Figure $\mathrm{S} 1 \mathrm{XRD}$ patterns and Rietveld refinement results (a) $\mathrm{LiMnPO}_{4}$, (b) $\mathrm{LiFePO}_{4}$, (c) $\mathrm{LiCoPO}_{4}$ and (d) $\mathrm{LiNiPO}_{4}$ samples. The insets are the SEM micrographs of the as-prepared samples. 

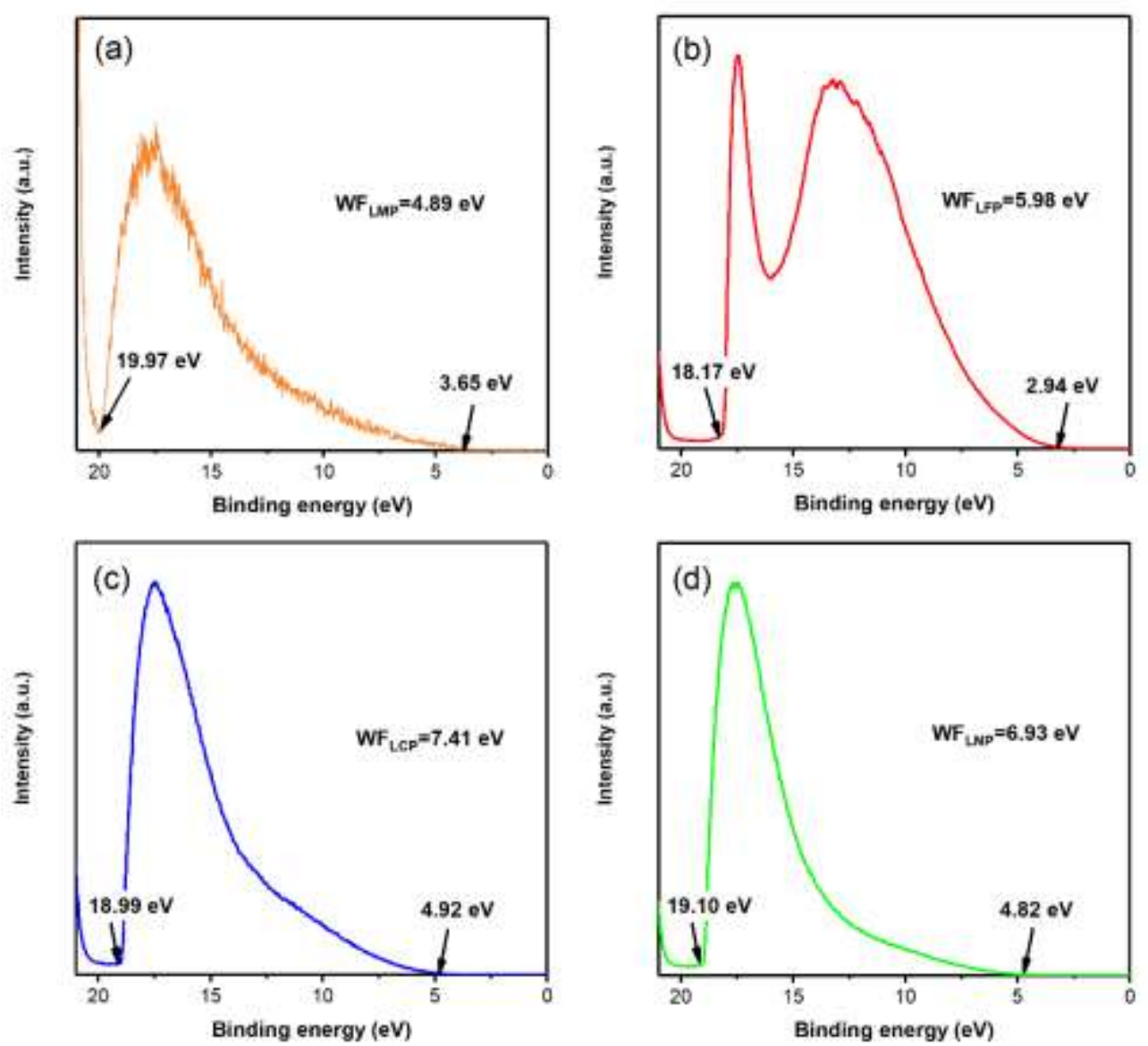

Figure 22 The UPS spectra for (a) $\mathrm{LiMnPO}_{4}$, (b) $\mathrm{LiFePO}_{4}$, (c) $\mathrm{LiCoPO}_{4}$ and (d) $\mathrm{LiNiPO}_{4}$ with He I radiation. 

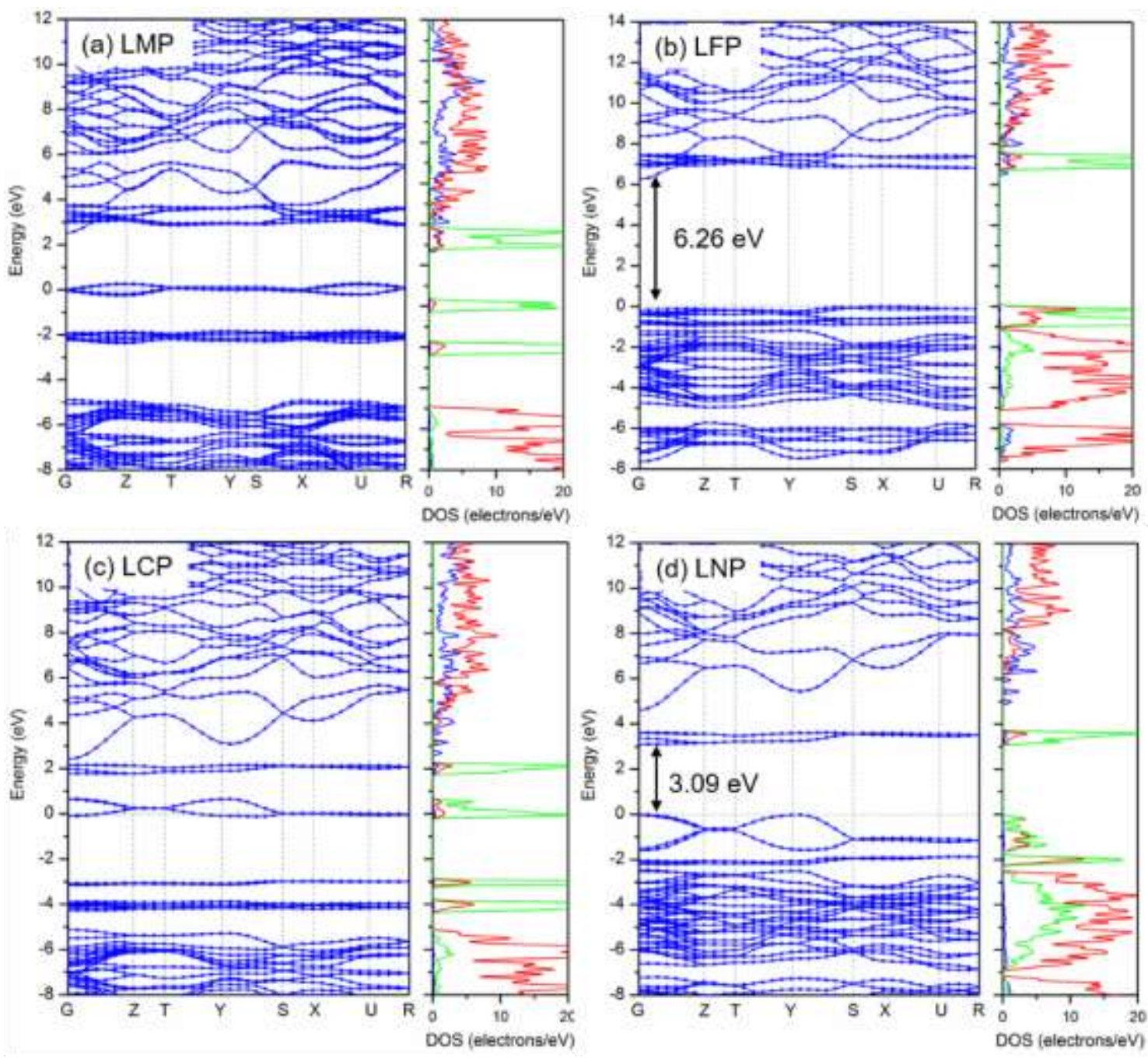

Figure S3 Estimated electronic band structures and density of states with sX-LDA for (a) LMP, (b) LFP, (c) LCP and (d) $L N P$ using no polarization and the energy mode. 

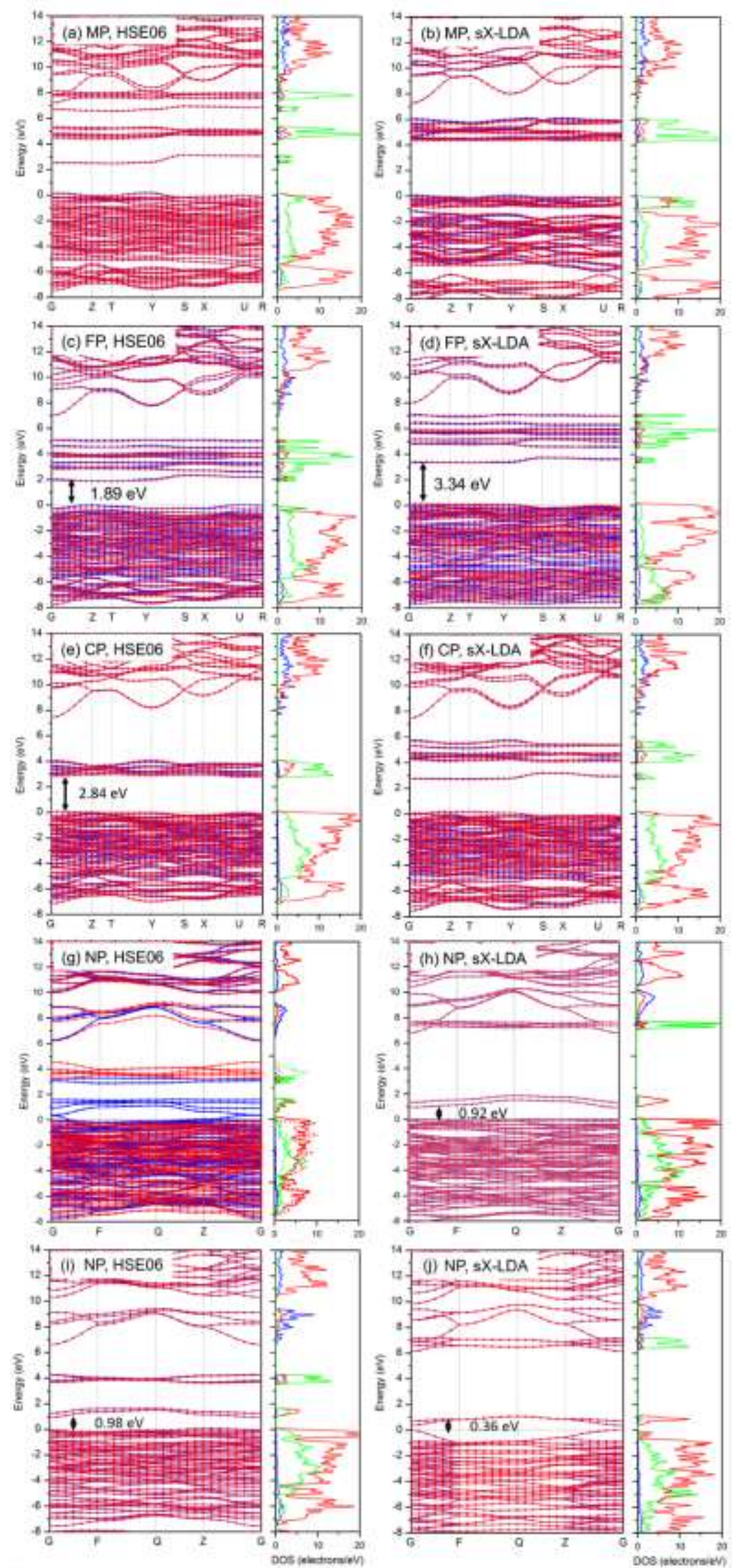

Figure $\mathrm{S} 4$ Estimated electronic band structures and density of states for delithiated phases, $(a-b) \mathrm{MnPO}_{4},(c-d) \mathrm{FePO}_{4},(e-f)$ $\mathrm{CoPO}_{4},(g-f) \mathrm{NiPO}_{4}$ with lattice parameters of $\mathrm{CoPO}_{4}(i-j) \mathrm{NiPO}_{4}$ with lattice parameters of $\mathrm{LiNiPO}_{4}$ using AFM configuration and the energy mode. 


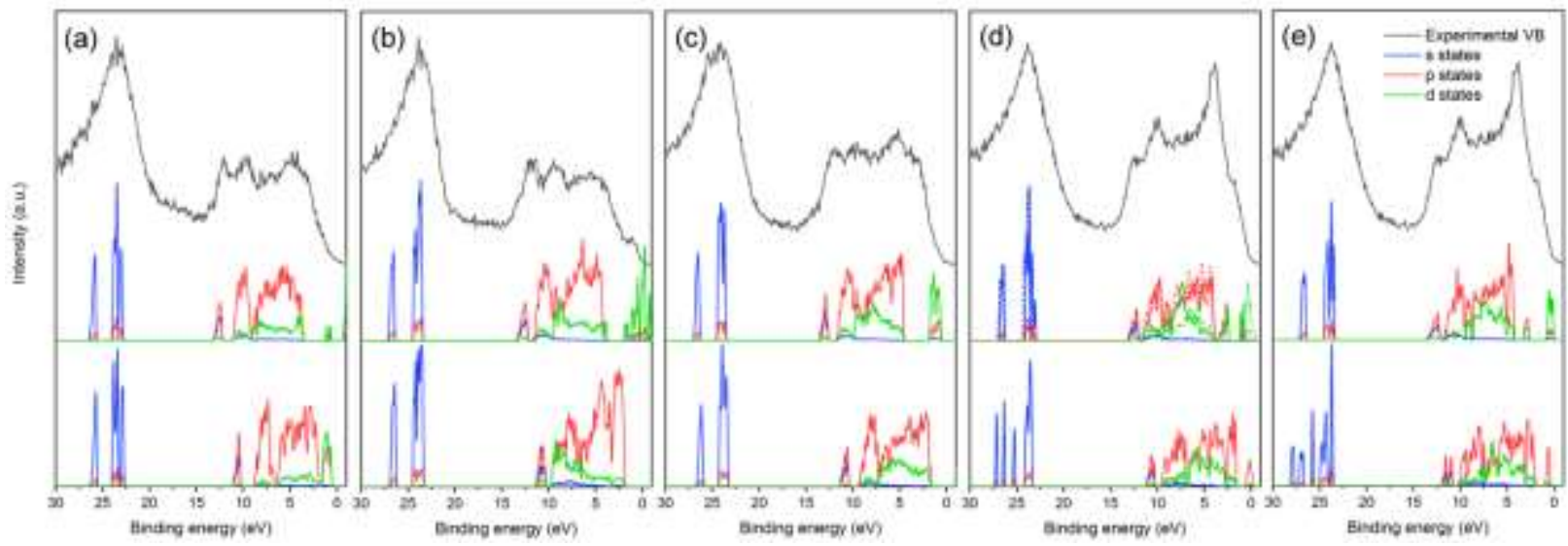

Figure S5 Comparison of experimental XPS valence band and estimated partial density of states (PDOS) for $(a) M_{n P O_{4},(b)}$

$\mathrm{FePO}_{4}$, (c) $\mathrm{CoPO}_{4}$, (d) $\mathrm{NiPO}_{4}$ with lattice parameters of $\mathrm{CoPO}_{4}$ and (e) $\mathrm{NiPO}_{4}$ with lattice parameters of LiNiPO 4 with HSEO6 (upper) and $s X-L D A$ (down). For the sake of comparison, DOS have been shifted in energy to coincide with the main experimental peak $\sim 25 \mathrm{eV}$. 


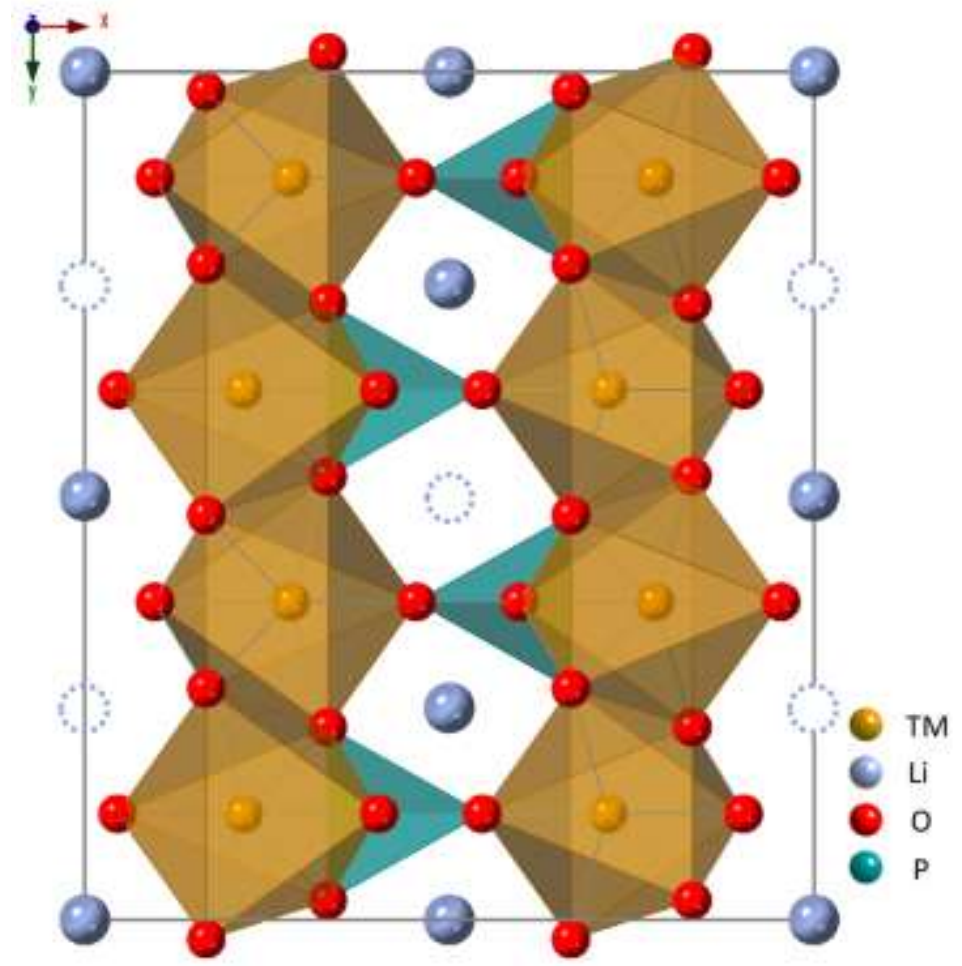

Figure S6 Structure model of the partially delithiated $\mathrm{LiTMPO}_{4}, \mathrm{TM}=\mathrm{Mn}, \mathrm{Fe}$, Co and $\mathrm{Ni}$. The hollow circles represent the vacancies resulting from delithiation. 